\title{
SYNTHESIS AND CHARACTERISATION OF
}

\section{NEW ANTIMALARIAL DRUGS}

\section{B. Jadhao}

Assistant Professor, Department of Chemistry, Dharampeth M. P. Deo Memorial Science College, Near Ambazari Garden, Nagpur - 440033 Corresponding author e-mail :drdbjadhao3@gmail.com

\section{Abstract:}

Malarial infections are still problem due to the adaption of the disease causing parasites to existing preparations of 8 - aminoquinoline compounds. For instance primaquine have been applied as chemotherapeutic agent for the treatment of malaria diseases. Introduction of methyl group at $4^{\text {th }}$ position and trifluorimethyl phenoxy group at $5^{\text {th }}$ position in primaquine modifies its biological activity. It is well known that the antimalarial activity of 6 -aminoquinoline compounds is similar to that of 8 -aminoquinolines. Thus newly synthesized compound has broad spectrum activity but unfortunetly, it is too toxic to be used as a human medicine. So structural modifications on such a nucleus are of great interest in the study of their biological activities. Synthesis of metal complexes of 2-[(2-chloroquinoline-3-yl) methylene amino] phenol $\left[\mathrm{M}(\mathrm{L})_{2}\right]$ is one such structural modification studied. The structures of these compounds have been established on the basis of conventional chemical transformations and IR, NMR and mass spectral analysis.

All these compounds are prepared to investigate their antibacterial and antifungal activities. It is observed that the above compound and their derivatives are found to be antibacterial and antifungal in nature. Further antimalarial activity investigations are in progress.

Keywords:Quinoline derivatives and their complexes, spectral data, Antimicrobial activity, Standred drug, UGC, CDRI

\section{Introduction:}

Despite years of continued efforts, malaria is still the number one infectious disease in the world. It remains a serious endemic disease in more than 90 countries in Africa, Asia and South America with 300 to 500 million new infections each year. Malaria causes more than one million deaths annually mainly affecting children and pregnant women. 
The situation regarding the control and treatment of malaria has progressively worsened with the spread of insecticide - resistant mosquito vectors and drug resistant parasite. Hence an urgent need for development of new active agent against multiresistant plasmodium strain through the identification of new targets which are critical for the disease process or essential for the survived of parasite. Various modified quinolines and related compounds shows some promise in this regards, so we planned to synthesise new quinoline derivatives and their related metal complexes.

\section{Experimental:}

\section{A. Synthesis of metal complexes of 2-[(C2-chloroquinoline-3-yl) methylene amino] phenol $\left[\mathrm{M}(\mathrm{L})_{2}\right]$ by classical method}

Metal (II) complexes were prepared by addition of $1 \mathrm{ml}$ of hot ethanol solution of $\mathrm{Zn}\left(\mathrm{CH}_{3} \mathrm{COO}\right)_{2}-2 \mathrm{H}_{2} \mathrm{O} \mathrm{Cu}\left(\mathrm{CH}_{3} \mathrm{COO}\right)_{2}$. $\mathrm{H} 2 \mathrm{O}, \mathrm{Hg}$ $\left(\mathrm{CH}_{3} \mathrm{COO}\right)_{2}, \quad \mathrm{Mn}\left(\mathrm{CH}_{3} \quad \mathrm{COO}\right)_{2}, \quad--\left(\mathrm{CH}_{3} \mathrm{COO}\right)_{2}, \quad \mathrm{Ni}\left(\mathrm{CH}_{3} \mathrm{COO}\right)_{2}, \quad 4 \mathrm{H}_{2} \mathrm{O}$ or $\mathrm{Co}\left(\mathrm{CH}_{3} \mathrm{COO}\right)_{2} \cdot \mathrm{H}_{2} \mathrm{O}$ into a hot ethanolic solution of 1 mole of ligand $(\mathrm{N}-$ [(2-chloroquineline-3-yl) -4-methyl benzenomine). The reaction mixture was then refluxed for about 5 hours. The precipitated solids were filtered. The precipitated solid product washed with hot ethanol and lastly with diethyl ether, which followed by drying is an oven.

\section{B. Synthesis of metal complexes of 2-[(C2-chloroquinoline-3-yl) methylene amino] phenol $\left[\mathrm{M}(\mathrm{L})_{2}\right]$ by MORE method}

Slurry of ligand was prepared in aqueous ethanol. To this, a solution of metal acetate in ethanol was added. The resulting mixture was irradiated in a microwave oven for $1.0-2.0$ min at medium power level $(600 \mathrm{~W})$ maintaining the occassional shaking. The hot reaction mixture was filtered, washed with hot ethanol and either, followed by drying in an oven. 
General representation for synthesis of metal complexes 2-[(2chloroquinaline -3-yl) methylene amino] phenol [M(L)2]

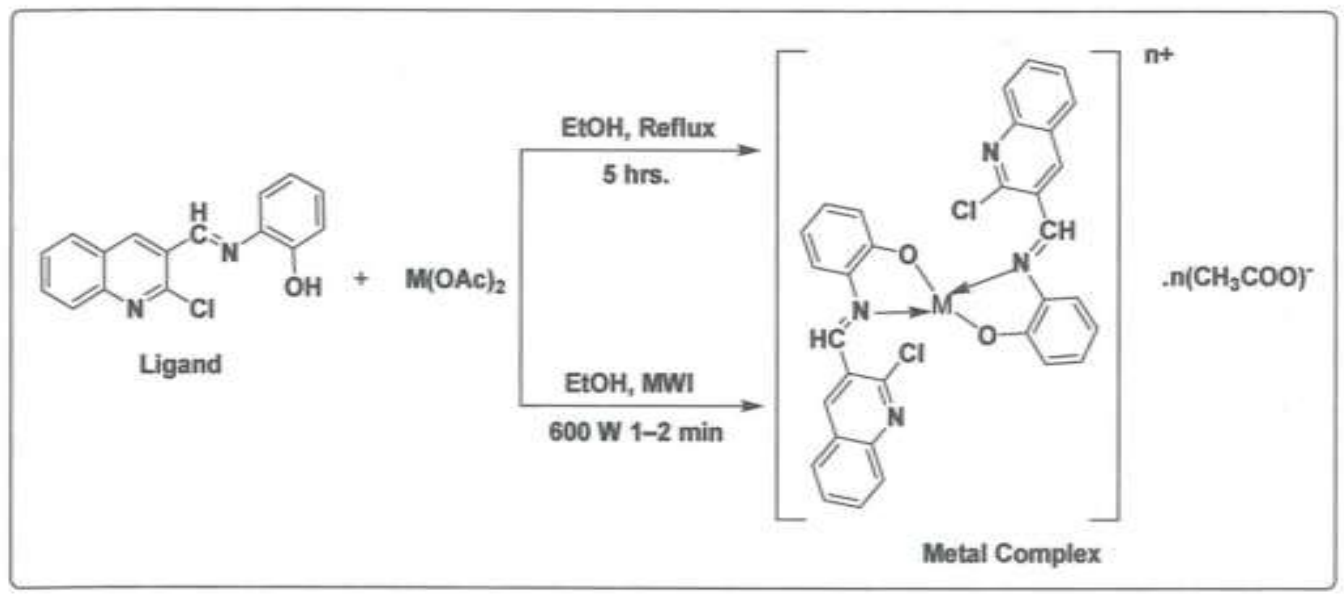

Fig. 1 : General representation of the applied method of synthesis by both classical and MORE technique. 5(a-f)

Figure 1 : General representation of the applied method of synthesis by both classical and more technique where $\mathrm{M}=\mathrm{Cu}(\mathrm{II}), \mathrm{Ni}(\mathrm{II})$, Co(II), Mn(II), Zn(II) ah Hg(II)

\section{Special Analysis:}

\section{Special data of Metal complex of 2-[(2-chloroquinolin-3-yl) methyleneamino] phonol}

The IR spectra provide valuable information regarding the nature of functional group attached to the metal. Infrared absorption of 2-[(2chloroquinoline-3-yl) methylene amino) phenol showing important band at $1590-1550 \mathrm{Cm}^{-1}$ attributed to $(-\mathrm{C}=\mathrm{N})$ mode is shifted to lower frequencies in the spectra of the complexes (1570-1520 $\left.\mathrm{cm}^{-1}\right)$ indicating $\mathrm{C}=\mathrm{N}-$ coordination to the metal. Strong bands at $1510-1490 \mathrm{~cm}^{-1}$ assigned to ring stretching of the five - membered ring several other absorptions associated with $\mathrm{C}-\mathrm{H}$ out of plane deformation made at 920$720 \mathrm{~cm}^{-1}$ undergo a slight positive shift due to decrease in eclectron density on the aromatic ring on complexation. Bands in the $460-360 \mathrm{~cm}^{-}$ ${ }^{1}$ range are assigned to $(\mathrm{M}-\mathrm{O})$ and $(\mathrm{M}-\mathrm{N})$ mode. 
Spectral data of N-[(2-chloroquinoline-3-yl) methylene] -4methylbenzene amine

H$^{1}$ NMR (400 MHz, DMSO-d6) 6 ppm:9.31 (s, 1H, - CH = N -), 2.42(- $\left.\mathrm{CH}_{3}\right)$, 7.80 - 8.24 (m, 9H, Ar-H). ${ }^{13}$ C NMR (200 MHZ, DMSO-d6) $\delta$ ppm : 127.3 $\left(\mathrm{C}_{\mathrm{a}}\right), 146.2\left(\mathrm{C}_{\beta}\right), 186.3(>\mathrm{C}=\mathrm{O}), 24.6\left(-\mathrm{CH}_{3}\right), 150.2$ (Cl-quinoline), 130.2 (C2-quinoline), 135.6 (C3-quinoline), 128.1 (C4-quinoline), 127.5 (C5uinoline), 130.8 (C6-quinoline), 127.4 (C7-quinoline), 126.4 (C8quinoline), 148.3 (C9-quinoline), 134.9 (Cl-Phenyl), 129.8 (C2-Phenyl), 129.6 (C3-Phenyl), 144.5 (C4-Phenyl), 129.6 (C5-Phenyl), 129.3 (C6Phenyl).

IR (KBr, v Cm${ }^{-1}$ ) : 1634 (C = N, quinoline), 3020 - 2950 (Aromatic C-H Str.), $1625(-\mathrm{CH}=\mathrm{N}$, imine $), 823(\mathrm{C}-\mathrm{Cl})$

MS (ESI) [ $\left.\mathbf{M}^{+}\right]$: 280 (100\%).

Comparision of Antimicrobial Activity of Synthesized compound with Standard drugs:

\begin{tabular}{|l|l|c|c|c|c|c|}
\hline Compound & Molecular formula & $\begin{array}{c}\text { S.aur } \\
\text { eus }\end{array}$ & Ecoli & $\begin{array}{c}\text { B. } \\
\text { sutilis }\end{array}$ & $\begin{array}{c}\text { S. } \\
\text { typhi }\end{array}$ & $\begin{array}{c}\text { A. } \\
\text { niger }\end{array}$ \\
\hline Ligand & $\mathrm{C}_{32} \mathrm{H}_{20} \mathrm{Cl}_{2} \mathrm{~N}_{4} \mathrm{O}_{2}$ & + & + & ++ & + & +++ \\
\hline $5 a$ & $\mathrm{C}_{32} \mathrm{H}_{20} \mathrm{Cl}_{2} \mathrm{~N}_{4} \mathrm{O}_{2} \mathrm{Zn}$ & + & ++ & ++ & + & +++ \\
\hline $5 b$ & $\mathrm{C}_{32} \mathrm{H}_{20} \mathrm{Cl}_{2} \mathrm{~N}_{4} \mathrm{O}_{2} \mathrm{Co}$ & + & ++ & ++ & +++ & +++ \\
\hline $5 c$ & $\mathrm{C}_{32} \mathrm{H}_{20} \mathrm{Cl}_{2} \mathrm{~N}_{4} \mathrm{O}_{2} \mathrm{Cu}$ & +++ & ++ & ++ & ++ & + \\
\hline $5 d$ & $\mathrm{C}_{32} \mathrm{H}_{20} \mathrm{Cl}_{2} \mathrm{~N}_{4} \mathrm{O}_{2} \mathrm{Ni}$ & ++ & ++ & ++ & +++ & +++ \\
\hline $5 e$ & $\mathrm{C}_{32} \mathrm{H}_{20} \mathrm{Cl}_{2} \mathrm{~N}_{4} \mathrm{O}_{2} \mathrm{Hg}$ & ++ & +++ & +++ & ++ & +++ \\
\hline $5 f$ & $\mathrm{C}_{32} \mathrm{H}_{20} \mathrm{Cl}_{2} \mathrm{~N}_{4} \mathrm{O}_{2} \mathrm{Mn}$ & +++ & ++ & +++ & ++ & - \\
\hline Ampicillin & $\mathrm{C}_{16} \mathrm{H}_{19} \mathrm{~N}_{3} \mathrm{O}_{4} \mathrm{~S}$ & $\begin{array}{c}12 \\
m m\end{array}$ & $\begin{array}{c}29 \\
m m\end{array}$ & $36 m m$ & 29 & - \\
& & - & - & - & - & $\begin{array}{c}18 \\
\text { fluconazole }\end{array}$ \\
\hline & $\mathrm{C}_{13} \mathrm{H}_{12} \mathrm{~F}_{2} \mathrm{~N}_{6} \mathrm{O}$ & & & & & $m m$ \\
\hline
\end{tabular}

The metal such as $\mathrm{Zn}$, Co, $\mathrm{Ni}$ and $\mathrm{Hg}$ in co-ordination with the quinoline based and Schiff's bases were found to be more potent than their ligands. So, compounds $5 a, 5 b, 5 d$ and $5 e$ were found to be more active. 


\section{Results ,Discussion and conclusion:}

The Schiff base 2-[(2-chloroquinoline-3-yl)methyleneamino]phenol was prepared by the condensation of 2-chloroquinoline-3-carbaldehyde and 2-amino phenol in ethanol classically and without usin solvent ethanol under MORE technique as shown in Fig.1. The transition metal complexes were then synthesized by the reaction of appropriate metal(II) salts with ligand traditionally and by MORE as shown in Fig. 1. The newly synthesized compounds were characterized by elemental analysis, $1 \mathrm{H}-\mathrm{NMR}$, mass, UV-Vis and FTIR spectroscopy studies. The data show that these complexes, ML2, are air-stable, non-hygroscopic, colored solids, insoluble in water and common organic solvents (alcohol, ethyl acetate, hexane, ether and toluene) and soluble in dimethyl sulfoxide (DMSO) and dimethylformamide (DMF). Physical characterization and comparative yield data of liand and complexes together with some physical properties are studied. It is clear from the data that the MORE technique for the synthesis of the complexes is high yielding, easy, convenient and ecofriendly as compared with the traditional method.

\section{Acknowledgement:}

The author (DBJ) is thankful to UGC for financial assistance to Minor Research Project on Synthesis of Metal Complexes of 2-[C-2Chloroquinoline-3-yl) Methyleneamino] phenol $\left[\mathrm{M}(\mathrm{L})_{2}\right]$ and CDRI, Lucknow, for Spectral Analysis.

\section{References}

Peters W., (1970). Chemotherapy and Drug Resistance in Malaria, Academic Press London - New York.

Peters W., and W. H. G. Richards, (1984). Antimalarial Drugs, Handb. Exp. Pharm. e, Springer Verlag, Berlin - Heidelberg - New York Tokyo.

Carson P. E., in ref. 2, 83. 
Sweeney T. R., in ref. 2, 325.

La Montagne M. P., P. Blumbers, (1982). J. Med. Chern., 25, 1094.

Nickel P., The Role of Quinoid Structures in Antimalarial Drugs.

Vierburton D., in ref. 2, 471.

WHO World Malaria Report 2005 (http://rbm.who.int/wmr2005).

Pukrittayakamee S., Imwong M., and Looareesuwan S., (2004). White N. Acta Tropica, 89, 351.

Bremen J. (2001). Am. J. Trop. Med. Hyg. 64

Dominguez J. N. (2002). Curr. Top. In Med. Chem. 2, 1171. 